\title{
Low-carbon LV networks: Challenges for planning and operation
}

DOI:

10.1109/PESGM.2012.6344760

Link to publication record in Manchester Research Explorer

\section{Citation for published version (APA):}

Ochoa, L. F., \& Mancarella, P. (2012). Low-carbon LV networks: Challenges for planning and operation. In IEEE Power and Energy Society General Meeting/IEEE Power Energy Soc. Gen. Meet.

https://doi.org/10.1109/PESGM.2012.6344760

\section{Published in:}

IEEE Power and Energy Society General Meeting|IEEE Power Energy Soc. Gen. Meet.

\section{Citing this paper}

Please note that where the full-text provided on Manchester Research Explorer is the Author Accepted Manuscript or Proof version this may differ from the final Published version. If citing, it is advised that you check and use the publisher's definitive version.

\section{General rights}

Copyright and moral rights for the publications made accessible in the Research Explorer are retained by the authors and/or other copyright owners and it is a condition of accessing publications that users recognise and abide by the legal requirements associated with these rights.

\section{Takedown policy}

If you believe that this document breaches copyright please refer to the University of Manchester's Takedown Procedures [http://man.ac.uk/04Y6Bo] or contact uml.scholarlycommunications@manchester.ac.uk providing relevant details, so we can investigate your claim.

\section{OPEN ACCESS}




\title{
Low-Carbon LV Networks: Challenges for Planning and Operation
}

\author{
Luis F. Ochoa, Member, IEEE, and Pierluigi Mancarella, Member, IEEE
}

\begin{abstract}
Many national and local governments have in recent years adopted feed-in-tariffs (i.e., above market price payments for energy produced) to incentivize consumers to install domestic scale generation (e.g., photovoltaic panels) in order to curb $\mathrm{CO}_{2}$ emissions. Electrical vehicles are also being encouraged by tax credits or grants in order to reduce the upfront investment. These incentives and potential future ones that could include more efficient ways of providing heat to households (e.g., electric heat pumps) are paving the way towards a low-carbon future that will make low voltage $(L V)$ networks, particularly urban ones, more active and with an increased demand. This scenario presents Distribution Network Operators (DNOs) with many planning and operational challenges requiring a paradigm shift. This panel presentation will discuss the technical impacts of these low-carbon technologies on urban LV networks, the potential solutions, and how the corresponding planning and operation aspects should be looked at in the future.
\end{abstract}

Index Terms - LV networks, distributed energy resources, PV panels, electric vehicles, electric heat pumps, storage, active network management, smart distribution networks.

\section{INTRODUCTION}

$\mathrm{I}^{\mathrm{N}}$ $\mathrm{N}$ order to meet the renewable targets set by the European Union in which $20 \%$ of electricity demand should be sourced by renewables by 2020 , governments have created different incentives to make domestic consumers adopt low carbon technologies.

Feed-in-tariffs (FIT) schemes, where local generation of electricity is rewarded (with payments above the market price), exist in some countries to particularly incentivize photovoltaic (PV) panels. This has been particularly successful in Germany. More recently, in the UK, the uptake has surpassed expectations given the generous FIT.

In countries where the bulk generation portfolio does not heavily rely on fossil fuel-based technologies, the electrification of transport could bring significant reductions in $\mathrm{CO}_{2}$ emissions. Hence, the adoption of electrical vehicles is also encouraged through tax credits or grants in order to help consumers with the upfront investment cost. However, no evidence of significant adoption has been seen in the last few years mainly due to cost and charging infrastructure aspects.

LF Ochoa and P Mancarella are with the Electrical Energy and Power Systems (EEPS) Group, School of Electrical and Electronic Engineering, The University of Manchester, Manchester M13 9PL, U.K.

(email: luis_ochoa@ieee.org,p.mancarella@manchester.ac.uk)
Similarly to the transportation case, decarbonization of the energy system as a whole requires dramatic reduction in the carbon footprint of the heating sector, currently dominated by oil and gas boilers and to a minor extent by electric heating. In this respect, electric heat pumps could lend themselves well to this purpose, with the potential of using (future) clean electricity to extract heat freely available in the environment (from air, ground, and so on) and bring it to a higher temperature suitable for space heating and domestic hot water generation. However, in spite of the great potential to provide cleaner heating by means of low carbon electricity, there will be serious challenges that the network, and in particular the LV one, will have to cope with.

While the future uptake of these low-carbon technologies is uncertain, Distribution Network Operators (DNOs) need to understand the potential impacts that different penetration levels of such new forms of load and generation might have on low voltage (LV) networks.

Traditional LV networks are perhaps the most passive circuits in distribution networks. Indeed, they are designed primarily using a 'fit and forget' approach where power flows go from the distribution transformer to the consumers and no element has to be operated or regularly managed. In fact, LV networks around the world lack observability. Different from higher voltage levels where a business case exists to monitor parts of the distribution network, it is not the case for LV. This lack of monitoring and of deeply understanding the behavior of LV networks and the consumers connected to them makes it even more challenging to assess the impacts of future scenarios.

This panel presentation will discuss not only the technical impacts of these low-carbon technologies on LV networks, but also the potential solutions and how the corresponding planning and operation should be approached in the years to come.

\section{Planning LV Networks}

LV networks are typically three-phase in European countries (differently from the single-phase design in the USA). In general, the following tasks are usually carried out to design a urban LV network (without considering protection aspects, voltage flicker, etc.):

- Evaluation of the total load to be supplied.

- Evaluation of the supply capacity of the existing network. 
- Determination of the number of substations required (and practical locations).

- Design of the layouts for the LV main corridors (also called distributors) and LV service cables.

- Determination of the cross sectional area for the main corridors (and sub sections).

The last task is based mainly on considerations of voltage drop which in turn is calculated, particularly in the UK, using the aggregated after diversity maximum demand (ADMD) of each (single-phase connected) customer. DNOs will adopt different ADMD for each customer according to its type (e.g., non-electric heating, electric heating, etc.). The most economic cable is then selected for which the voltage drops at the customer connection points are within the statutory limits.

While the corresponding calculations can also consider demand growth (if not already embedded through the ADMD), it is certainly not current practice to take account of new forms of loads such as electric heat pumps or electric vehicles (given the yet uncertain future uptake of these technologies). However, domestic scale generation, such as PV panels or micro Combined Heat and Power (micro CHP), are indeed being considered by some DNOs by assessing scenarios such as zero generation-maximum demand and aggregated nominal generation-minimum demand. Nonetheless, while these considerations might be enough for low penetration levels of these devices, the potential impacts that medium to high penetrations might have on the LV network are actually not being catered for.

\section{OPERATING LV NETWORKS}

As mentioned previously, LV networks are traditionally designed adopting a 'fit and forget' approach. DNOs want to minimize any operation (if at all) to be carried out in LV circuits in order to reduce costs. Consequently, distribution transformers for LV networks (e.g., $11 \mathrm{kV} / 0.4 \mathrm{kV}$ ) do not have on-load tap changers (OLTCs). Given that the 'typical' domestic load is well known, transformers with off-load tap changers suffice to cope with voltage drops.

In most cases, LV networks are operated radially. Particularly in urban areas, it is common to have link boxes to allow the connection of LV circuits to other feeds due to maintenance or faults. In some specific cases, LV networks might be operated in an interconnected fashion, where two LV distribution substations supply power to the circuit.

While, to date, current operational practices of LV networks have proven cost-effective, the mass adoption of low-carbon technologies by residential consumers will potentially require a more active management of these circuits.

\section{THE CHALLENGES}

\section{A. Domestic-Scale Generation}

Small-scale generation (or domestic-scale generation) will in some cases create reverse power flows. Depending on the electricity consumption behavior of households, the penetration and generation profile of the corresponding (similar) generators, and their locations in the LV feeder, significant reverse power flows might occur. This could result in a voltage rise that, depending on the time of the day, could even go above the statutory limit. The lack of OLTC capabilities in LV transformers makes it difficult to set a fixed voltage on the secondary that could cope with a wide range of voltages. In addition, given that domestic-scale generators are typically single-phase connected, voltage unbalances might increase.

The dependence of PV panels on the weather conditions makes this particular technology even more challenging with high penetrations. Sudden generation peaks as well as sudden drops of generation output (due to clouds) are very common, increasing the challenge of managing voltage variability (and the corresponding effects on power quality).

\section{B. New Forms of Load}

The electrification of heat and transport might pose a significant burden to existing LV networks. Single-phase connected heat pumps might add even more than $5 \mathrm{~kW}_{\mathrm{e}}$ load to a normal household load (with typical ADMD between 1 and $1.5 \mathrm{~kW}_{\mathrm{e}}$ ) in a winter cold day (when the heat pump is less efficient and may require electric backup heating). A similar situation occurs with electric vehicles. Depending on their charging mode a household could increase its maximum demand by a few $\mathrm{kW}$. A high uptake of these technologies by domestic consumers will undoubtedly have both thermal (capacity of the LV feeder and transformer) and voltage regulation (voltage drops, unbalances, etc.) implications, as well as an increase in energy losses.

\section{CONCLUSIONS}

This panel session will expand the discussion on the technical impacts of (high penetration of) low-carbon technologies on LV networks. The different challenges faced by distribution planners and operators will also be addressed with particular emphasis on the new technologies and active management approaches that could be used to tackle voltage and thermal issues in LV feeders and distribution transformers.

Luis F. Ochoa (S'01-M'07) is a Lecturer in Smart Distribution Networks at The University of Manchester, UK. He received the B.Eng. degree from UNI, Lima, Peru, in 2000 and the M.Sc. and Ph.D. degrees from UNESP, Ilha Solteira, Brazil, in 2003 and 2006, respectively. From 2007 to 2010, he was a Research Fellow at the University of Edinburgh, U.K.

His current research interests include network integration of distributed energy resources and distribution system analysis.

Pierluigi Mancarella (M'08) received the Ph.D. degree in electrical engineering from the Politecnico di Torino, Torino, Italy, in 2006. Currently, he is a Lecturer in Sustainable Energy Systems at The University of Manchester, UK. Previously, he was a Research Associate at Imperial College London, London, U.K.

His research interests include distribution networks, distributed energy resources and multicarrier energy systems, as well as integration of demand and renewable energy sources into power systems. 